\title{
Концепция права международной торговли во французской доктрине
}

Хомякова Н.П. ${ }^{*}$

Настоящая статья представляет концепцию права международной торговли во французской доктрине посредством анализа учебника под тем же названием, широко используемого во Франции. В этой связи, в статье кратко рассматривается следующий перечень проблем: предмет права международной торговли, его источники и «игроки» - I глава; сделки, заключаемые в рамках права международной торговли - II глава; разрешение споров (органы государственной юстиции, международный арбитраж) - III глава учебника. В заключении статьи излагается контекстный метод обучения, рекомендуемый автором настоящей статьи для овладения иноязычной профессиональной компетенцией.

Ключевые слова: право международной торговли; урегулирование споров; контекстный метод обучения.

Настоящая статья содержит анализ концепции права международной торговли, выдвинутой известными французскими юристами, специалистами в рассматриваемой области - Жаном-Мишелем Жакэ / Jean-Michel Jacquet, Филиппом Дэлёбеком / Philippe Délebeque, Сабиной Корнэлу / Sabine Corneloup. Эта концепция легла в основу учебника под тем же названием «Право международной торговли»/ "Droit du commerce international" указанных авторов, широко используемого в университетах Франции при подготовке юристов соответствующего профиля ${ }^{1}$.

В первой главе учебника французские исследователи представляют историю развития права международной торговли и рассматривают его предмет, иели, источники и участников. Они связывают становление международной торговли как самостоятельной отрасли права с послевоенными годами, отмеченными небывалым взлетом товарои финансопотоков. При этом начиная с 70-х годов прошлого столетия наряду со сферой торговли широко развилась сфера предоставления

\footnotetext{
${ }^{*}$ Хомякова Н.П. - к.п.н., доцент кафедры французского языка №1 МГИМО (У) МИД РФ. homyakova@rambler.ru.

${ }^{1}$ Jean-Michel Jacquet, Philippe Délebeque, Sabine Corneloup. Droit du commerce international. P, Dalloz, 2007.
} 
услуг, которая в настоящее время опережает первую. Одновременно государства мира оказались перед необходимостью решать проблемы международных инвестиций, связанные с интернационализацией производства, осваивать зарубежные рынки, решать специфику передачи прав на интеллектуальную собственность. Очевидность и сложность указанных проблем вынудила их координировать свою торговую политику на региональном и мировом уровне, следствием чего явилось создание ГАТТ, Евросоюза и ВТО. При этом сквозь призму собственно торговой политики все мировое сообщество было призвано разрабатывать общую стратегию и устанавливать правила поведения в сферах, не подпадающих под традиционное понимание международной торговли, таких как: защита окружающей среды, здравоохранение, недобросовестная конкуренция, социальное измерение. Указанный многофакторный контекст породил новую комплексную отрасль права - право международной торговли, вбирающую в себя элементы гражданского и торгового права, производного от них морского, а также международного частного права.

Будучи самостоятельной отраслью, в соответствии с французской доктриной, право международной торговли имеет свои цели, свой предмет, источники и участников.

Ее иель состоит в том, чтобы обеспечить регулирование посредством определенной совокупности инструментов права те правоотношения, которые возникают между участниками / «операторами» экономической деятельности в связи с совершаемыми ими разносторонними действиями / сделками. Уточняя предмет деятельности, которая лежит в основе права международной торговли, авторы указывают, что термин экономическая / activité économique имеет здесь принципиальное значение. Вытесняя термин коммерческий, коммерческая / commerciale, он толкуется широко и носит собирательный характер. Так, внешнеэкономические операции / activités économiques понимаются как вбирающие в себя два типа операций: юридические и материальные. Юридические операции обусловлены действиями самих участников международной торговли (например, урегулирование споров, возникающих между сторонами в договоре). Материальные операции охватывают договоры, касающиеся материального и нематериального имущества: договоры купли-продажи, внешнеторгового обмена, патентных лицензий. Сюда же относятся транспортные торговые операции, осуществляемые воздушными, морскими, железнодорожными и автодорожными 
средствами, дистрибуторские международные договоры, комплексные договоры, такие как франшиза, договоры о посреднических услугах и о предпринимательстве, сохраняющие свою значимость в случае разобщенности партнеров по договору, несмотря на развитие электронных средств связи. Экспорт и импорт, операции займа и аренды, которые осуществляются за пределами одного государства, также являют собой механизмы, посредством которых осуществляется сегодня мировая торговля. Размещение за границей своих предприятий (что рассматривается сегодня как привычный и неизбежный элемент внешнеэкономической деятельности) сопряжено с необходимостью прибегать к созданию различных по форме товариществ: в этом право международной торговли тесно соприкасается с правом международных инвестиций сферой, также восходящей к экономической правовой регламентации.

Раскрывая предмет права международной торговли, авторы анализируемой концепции отдельно останавливаются на понимании ими выражения международный характер внешнеэкономической деятельности. Они указывают, что наиболее распространенное понимание состоит в том, чтобы связать это понятие с каким-либо иностранным элементом/élément d'extranéité конкретного правоотношения. Речь может идти о разном гражданстве сторон в договоре, месте жительства или постоянном месте пребывания. Речь может идти также о месте заключения или исполнения договора, месте возникновения непредвиденного обстоятельства или нахождения товара.

Источники права международной торговли подразделяются авторами анализируемой концепции на источники-средства и источники-норMbl. Источники-средства связаны с непосредственной деятельностью участников/ «операторов» и включают: индивидуальные и коллективные договоры, торговые обычаи, общие принципы права. Источникинормы права охватывают три группы норм, относящихся к внутригосударственному праву, праву сообществ, транснациональным нормам.

Уникальность транснациональных норм в соответствии с позицией авторского коллектива состоит в том, что они освобождены как от требований внутренних законодательств, так и от требований международного правопорядка. В работе подчеркивается, что, хотя внутреннее законодательство в силу той высокой степени разработанности, которой оно достигло во многих странах, способно разрешить большинство проблем, выведенных на уровень международных договорных отношений, специфика некоторых из них (например, коллизия 
законов) требует применения особых норм регулирования. Унифицированное право как раз и являет собой тот эффективный инструмент, который позволяет сократить препятствия на пути международного товарообмена.

Субъекты права международной торговли делятся авторами анализируемой концепции на «публичных игроков» / “acteurs publics” и «частных игроков» / “acteurs privés”. Первым по значимости публичным игроком выступает государство, поскольку эффективность функционирования международной торговой системы во многом зависит от его нормотворческой и правоприменительной активности. Она направлена на таможенное регулирование, лицензирование и котирование экспорта и импорта, валютные операции, содействие развитию внешней торговли и др. Эта многоаспектная интенсивная деятельность осуществляется во Франции через посредство следующих специализированных государственных структур: Управление по внешнеэкономическим связям / La Direction des relations économiques extérieures (Dree); Франиузское агентство по содействию развитию международных компаний / L'Agence Française pour le développement international des entreprises (UBI France); Франиузская компания страхования внешнеэкономических операций / La compagnie française d'asurance pour le commerce extérieur (COFACE).

Другими субъектами права международной торговли являются сnециализированные международнье организации/les organisations internationales spécialisées. К ним относятся: Комиссия ООН по праву международной торговли (ЮНСИТРАЛ) / La conférence des nations unies sur le commerce et le droit (CNUDCI); Всемирная организация интеллектуальной собственности (ВОИС) / L'organisation mondiale de la propriété intellectuelle (OMI); Международная организация гражданской авиации / L'organisation de l'aviatoin civile internationale; Международный институт по унификации частного права (Унидруа) / L'institut international pour l'unification du droit privé(Unidroit) и др.

Всемирная торговая организация (ВТО) / L'organisation mondiale du commerce (L'OMC) квалифицируется профессором Жакэ и его коллегами как «глобальный игрок». В работе представлена история становления ВТО - наследницы ГАТТ, подробно рассматривается содержание всех циклов (раундов) ее деятельности. Сегодня ВТО - это мощная международная организация, обладающая правосубъектностью и объединяющая большинство государств мира. В основу ее правопорядка положены два 
принципа: принциип недискриминациии / le principe de non-discrimination и принциип защчиты национального рынка через таможенные пошлины и их консолидацию / le principe de la protection du marché et de la production nationale d'un Etat par les droits de douane et leur consolidation.

В качестве «частных игроков» - субъектов права международной торговли рассматриваются торговые товарищества и их объединения.

Во второй главе анализируемого учебника, озаглавленной «Сделки, регулируемые правом международной торговли» / "Les opérations du commerce international”, значительное место отводится рассмотрению определения права, применимого к международным коммерческим договорам. При решении этой проблемы французская доктрина учитывает прежде всего волю сторон, подчеркивая значимость принципа автономии воли в этой сфере права. В соответствии с позицией французских ученых данный принцип являет собой мощный фактор прогнозируемости поведения сторон и юридической защищенности их договора. Вместе с тем его применение сопряжено с возникновением определенных трудностей. Эти трудности возникают тогда, когда стороны указывают в качестве применимого права нормы, относящиеся к различным системам правопорядка, или когда стороны опираются на отдельные положения закона какой-либо страны, не подчиняя свой договор в целом ее законодательству. Такие факторы вынуждают составлять сложные оговорки к заключаемому договору, с трудом в него инкорпорируемые. Их снятию во многом способствует Римская конвенция 1980 года о праве, применимом к договорным обязательствам 1991 / La convention de Rome de 1991 sur la loi appicable aux obligations , широко используемая в судебной практике стран Евросоюза, и во Франции в частности. Так, данная конвенция предусматривает понятие «дуалистической коллизионной нормы» / une règle de conflit dualiste, основанной прежде всего на учете принципа автономии воли, пополняемого «коллизионной нормой с объективной привязкой»/une règle de conflit à rattachement objectif в случаях, когда стороны явно не выразили свою волю (под «объективной привязкой» здесь понимается указание на место нахождения товара и на место постоянного пребывания одной из сторон в договоре). Французскими учеными подчеркивается, что опора на принцип автономии воли делает невозможным использование некоторых других норм права: таковой является прежде всего «норма обратной связи» / renvoi, а также «оговорка об исключении» / clause d'exception, несовместимость которой с принципом автономии 
воли подтверждается ст. 15 Римской конвенции. Положения Римской конвенции пополняются содержанием Регламента Европейской комиссии о праве, применимом к договорным обязательствам, называемым «Рим-1» / Règlement de la comission européenne sur la loi applicable aux obligations contractuelles - Rome I, 2005. Первая важная инновация Регламента содержится в его статье 3-1, которая устанавливает, что «выбор сторонами применимого права может быть выражен явно или следовать совершенно очевидным образом из положений договора, поведения сторон, а также обстоятельств дела». Вторая важная инновация содержится в статье 3-3 Регламента, допускающей выбрать в качестве применимого права не только национальное право, но и «принципы, нормы материального права, признанные на международном и европейском уровнях, каковыми являются, в частности: Принципы международных коммерческих договоров Унидруа, 2004 / Les Principes Unidroit pour les contrats du commerce international, Принципы европейского договорного права (работа продолжается) / Les Principes du droit européen du contrat.

В случае отсутствия выбора сторон рекомендуется применять положения Регламента, изложенные в его четвертой статье, касающиеся восьми наиболее распространенных типов договоров. Другие договоры должны регулироваться законом той страны, в которой сторона, осуществляющая «характерное исполнение» в момент заключения договора/la prestation caractéristique du contrat имеет свою постоянную резиденцию (соотносится с принципом «тесной связи», согласно статье 4 Римской конвенции).

Далее во второй главе описываются содержание и инструменты регулирования различных типов договоров/сделок, объединяемых авторами учебника в следующие группы: договоры купли-продажи и перевозки, определяемые как «сердце международной торговли»; договоры поручения и представительства, отражающие правоотношения, возникающие между участниками - «операторами» права международной торговли и их клиентурой; дистрибуторские договоры и договоры предоставления услуг; договоры финансирования, выступающие «определяющим фактором» международного товарообмена. Последние остаются «центральным нервом» расчетно-кредитных отношений внешнеэкономической деятельности.

В этой же главе рассматриваются проблемы инвестирования, коммерческой несостоятельности и конкурентного производства, характеризующие сегодняшнее право международной торговли. 
Третья глава анализируемого учебника посвящена урегулированию споров в области международной торговли / Règlement des litiges du commerce international. Французские ученые указывают, что в некоторых случаях бывает возможно прибегнуть к альтернативным способам их разрешения / Règlement alternatif des différends (ADR), каковыми являются согласительная процедура / la conciliation и медиация/ la médiation. Однако чаще всего обстоятельства вынуждают стороны добиваться решения, имеющего юрисдикционный характер, обязательного для выполнения. Такого рода решение может быть вынесено либо органами государственной юстиции, либо международным арбитражным судом.

Подсудность французской государственной юстиции применительно к спорам, осложненным иностранным элементом, реализуется на основе соответствующих положений «общего права»/droit commun или норм европейского права. Первая из этих возможностей сопряжена прежде всего с применением статей 14 и 15 Французского гражданского кодекса (ФГК): статья 14 позволяет французскому гражданину-истцу вызвать во французский суд иностранца-ответчика, а статья 15 позволяет истцу-иностранцу вызвать во французский суд ответчика-француза.

Указанные статьи ФГК в значительной степени пополнены положениями статей 42 и 46 Нового процессуального кодекса / Nouveau Code de Procédure Civile (NCPC). Так, статья 45 этого кодекса устанавливает, что «территориально компетентной судебной инстанцией является, если не указано иное, суд, находящийся по месту жительства ответчика». Статья 46 добавляет к этому, что «истец может обратиться, помимо суда, находящегося по месту жительства ответчика, в суд по месту поставки товара или исполнения услуги».

Вместе с тем совершенно очевидно, что в вопросе о рассмотрении споров по внешнеэкономическим сделкам французское правосудие широко опирается на положение региональных международных соглашений. Важнейшим из них на современном этапе развития внешнеэкономических отношений является Брюссельская конвенция о подсудности и приведении в исполнение судебных решений по гражданским и коммерческим спорам, 1968 / La convention de Bruxelles concernant la compétence judiciaire, la reconnaissance et l'exécution des décisions en matière civile et commerciale de 1968. Положения этой конвенции были распространены на Луганскую конвенцию 1988 года того же названия, а затем пополнены регламентом совета ЕС за номером 44/2001 
2000 года, получившим наименование Регламент Брюссель-I / Le Règlement du Conseil concernant la competence judiciaire, la reconnaissance et l'exécution des décisions en matiere civile et commerciale du 22 decembre 2000 (Règlement Bruxelles-I). Указанные инструменты права применяются к любым гражданским и торговым спорам, за исключением тех, которые касаются имущественных прав, возникающих из брачных отношений и завещаний, банкротства, проблем арбитража. Они представляют собой основополагающие соглашения в области международного гражданского процесса, позволяющие разрешать конфликт юрисдикций/conflit de juridictions, предусматривающие эффективный механизм признания и исполнения иностранных решений, который позволяет отразить процессуальные формальности и существенно ускорить экономический оборот. Благодаря этим инструментам было сформировано единое правовое пространство для признания и исполнения судебных решений, а также новая система международной юрисдикции судов.

Другим способом разрешения споров, включающих иностранный элемент, является международный арбитраж. Наши французские коллеги подчеркивают, что арбитражное правосудие познало в современную эпоху невиданный взлет именно в сфере международной торговли. Этот фактор они объясняют тем, что арбитражное правосудие отвечает «ожиданиям»/attentes участников внешнеэкономических связей, связанным с преодолением неудобств и слабостей органов государственной юстиции. «Ожидаемые» преимущества связаны прежде всего с окончательностью и обязательностью арбитражных решений, выносимых по существу в одной инстанции/sans appel. Далее, если жесткие правила судопроизводства, характеризующие государственную юстицию, влекут за собой подчас установление достаточно травматичной обстановки, в которой проходят прения сторон (что препятствует их откровенному обмену мнениями и не способствует урегулированию конкретных отношений), то арбитражное судопроизводство характеризуется большей гибкостью в связи с тем, что оно осуществляется на основе права, избранного самими тяжущимися или их арбитрами. При этом сами арбитры также выбираются сторонами в споре и пользуются их полным доверием: естественно, что партнеры по сделке обращаются к профессионалам, глубоко сведущим в спорном вопросе, в то время как судьи государственных судов не всегда обладают должной компетенцией в сфере внешнеэкономических отношений. 
Однако главное преимущество арбитража, по сравнению с государственным правосудием, состоит в невозможности для последнего создать «нейтральное поле» для обеих сторон в споре, представляющих разные государства, поскольку для судьи (как это нередко отмечалось) всегда будет ближе позиция его соотечественников, с которыми его связывает общее культурное наследие, находящее свое отражение в лингвистическом, экономическом и особенно юридическом аспекте.

Вместе в тем, согласно позиции авторов анализируемой работы, государственное и арбитражное правосудие не следует рассматривать как взаимоисключающие сферы права; они дополняют друг друга. Эта комплементарность/complémentarité структурируется на трех уровнях: на уровне координации/coordination, на уровне сотрудничества / collaboration, на уровне верховенства государственной юстииии / la prévalence de la juctice étatique sur la justice arbirtale, что закреплено статьями 1458 и 1493 Нового процессуального кодекса Франции.

Представленный краткий анализ концепции права международной торговли, разработанной профессором Жакэ и его коллегами, позволяет сделать вывод о том, что она, несомненно, близка многим положениям национальной российской доктрины. В наибольшей степени она роднится, на наш взгляд, с содержанием концепции профессора А.А. Костина «Правовое регулирование внешнеэкономических связей» (ПРВЭС $)^{2}$, отраженной в его одноименном курсе. Данный курс опирается на положения отечественного и зарубежного гражданского и торгового права, предполагая их предварительное изучение, отводит значительное место международному частному праву (МЧП), регулирующему гражданско-правовые отношения, в которых присутствует иностранный элемент, чтобы затем перейти к рассмотрению собственно регулирования внешнеэкономических связей.

Определенную созвучность рассмотренной концепции права международной торговли мы находим и в трудах других представителей российской доктрины: А.С. Комарова ${ }^{3}$, М.М. Богуславского ${ }^{4}$, Н.И. Марышевой 5 .

\footnotetext{
2 Костин А.А. Правовое регулирование внешнеэкономических связей: Учебник по публичному и гражданскому праву. В 2 томах. Том II. Частное право. М.: Статут, 2008.

3 Комаров А.С. (под редакцией). Правовое регулирование внешнеэкономической деятельности. М.: ДеКА, 2001.

${ }^{4}$ Богуславский М.М. Международное частное право. М.: Юрист, 2004.

${ }^{5}$ Марышева Н.И. Международное частное право. М.: Юрист, 2004.
} 
Таким образом, общий вывод, который нам представляется логичным сделать из представленного нами краткого обзора известного французского учебника, состоит в том, что он содержит оригинальную и вместе с тем во многом корреспондирующую с позицией российских ученых концепцию, отражающую комплексную и многоаспектную проблематику современной международной торговли, что делает его несомненно полезным и достойным для изучения. Нет сомнения в том, что овладение материалами данного глубоко специализированного учебника, как и других ценных аутентичных юридических материалов, раскрывающих перед обучающимися правовую культуру страны изучаемого иностранного языка, наиболее полно и эффективно реализуется в курсе по языку специальности. В этой связи кратко остановимся, заключая нашу статью, на тех методах и приемах обучения, которые современная педагогическая наука рекомендует использовать в процессе профессионально ориентированной иноязычной подготовки студентов.

Ведущей универсальной педагогической теорией, получающей все большее распространение в профессиональном образовании и обусловливающей используемые в нем методы, приемы и технологии, является, по мнению многих ученых, теория контекстного обучения, разработанная А.А. Вербицким 6 и представителями его школы.

Контекстное обучение - это обучение, в котором с помощью всей системы дидактических форм, методов и средств, традиционньх и новых, моделируется предметное и социальное содержание будущей профессиональной деятельности специалиста, а усвоение им абстрактных знаний, как знаковых систем, наложено на канву этой деятельности. Применение теории контекстного обучения в учебном процессе диктует необходимость его структурирования с опорой на ряд принципов, важнейшие из которых представлены ниже.

Так, принции учета контекстов профессиональной деятельности какой-либо категории специалистов в процессе их иноязычной профессионально ориентированной подготовки означает, что курс по языку специальности для этой категории специалистов должен строиться на основе определенных категорий, отражающих содержание контекстов их будущего труда, каковыми являются:

Принцип проблемности содержания обучения и его развертывания в образовательном проиессе знаменует собой переход

${ }^{6}$ См. подробно: А.А. Вербицкий 1999, 2000, 2004, 2006. 
- Репертуар специальных (правовых) текстов по определенной тематике, являющихся источником профессио-нальных знаний, выступающих в учебном процессе в качестве ориентировочной основы практических действий для последующего решения типовых и проблемных задач;

- реестр функциональных ролей этих специалистов, указывающий на те социальные функции, которые они призваны выполнять на производстве;

\section{- перечень типичных для них ситуа-} ций профессиональной деятельности, каждая из которых выступает ориентиром для отбора/разработки соответствующих проблемных заданий;

- совокупность сфер и подсфер профессионального общения, указывающих на те виды и жанры дискурсов, которыми надлежит овладевать конкретной категории обучающихся для возможности их эффективного участия в межкультурном профессиональном общении.
Контексты учебного предмета и научного знания определенной сферы образования (юриспруденции), отражающие две сопоставляемые (правовые) культуры

Социокультурный контекст, сопряженный с определенной сферой образования (юриспруденцией), отражающий две сопоставляемые (правовые) культуры

от преимущественно регламентирующих, алгоритмизированных, программированных норм и методов организации дидактического процесса в вузе к развивающим, проблемным, исследовательским, поисковым. В силу этого принципа в курсе по языку специальности рекомендуется практиковать наряду с традиционными заданиями (реферирование, перевод) технологии проблемного типа. Подобные технологии развивают в едином потоке учебного процесса не только специальные лингвистические компетенции, но и собственно профессиональные качества: соответствующие способы мышления, профессиональную мотивацию.

В работе со студентами-юристами, изучающими французский язык, рекомендуется использовать нижеследующие технологии проблемного типа, традиционно применяемые во франко-германской системе подготовки юристов и имеющие аналоги в российской системе образования. 
Одни из них моделируют уровень интеллектуальной активности, а другие (комплексные) моделируют одновременно уровень интеллектуальной и социальной активности ${ }^{7}$.

\section{Вынесение решения по практической ситуации/} делу, называемое также казусом, юридической задачей ${ }^{8}$ - Cas pratique9;

Комментирование постановления суда - Commentaire d'arrêt ${ }^{10}$;

Написание профессионального эссе - Dissertation juridique ${ }^{11}$.

Технологии проблемного типа, моделирующие интеллектуальную активность

\section{Проведение деловой игры, разыгрывание про-} фессионально ориентированных ситуаций, имитирующих проведение научных форумов, заседаний суда, арбитражей - Jeux de rôle, Tenue des colloques; Simulation des audiences, Simulation des arbitrages.

Комплексные технологии проблемного типа, моделирующие интеллектуальную и социальную активность

Принциип межпредметной координациии/принции межпредметносmи предусматривает целенаправленное согласование содержания различных дисциплин с целью формирования в сознании обучающихся целостного восприятия предметов и явлений окружающего мира. В рамках дисциплины «Язык специальности» междисциплинарная

${ }^{7}$ Следует указать, что, хотя обе ветви проблемного типа способствуют эффективности речемыслительной деятельности, они имеют каждая свою специфику. Так, если технологии, основанные на проблемной ситуации моделируют условия творческой мыслительной активности на основе проблемной ситуации, то комплексные технологии позволяют моделировать также и условия социальной активности. В условиях игры студент активен двояко: исполняя свою роль специалиста и члена коллектива [А.А. Вербицкий 1999, 2004, 2006]. К этому следует добавить, что комплексные технологии несомненно способствуют развитию профессионального группового мышления специалистов, что рассматривается как одна из важнейших задач высшей школы сегодня [М.А. Матюшкин, 2003].

8 См.: Васильев Е.А. Практикум по гражданскому и торговому праву зарубежных государств. М.: Международные отношения, 2005.

См.: Кабатов В.А. Практикум по гражданскому праву Российской Федерации. М.: МГИМО, 2001.

${ }^{9}$ См.: Mouralis J-L. Le Cas pratique en droit civil. P., 2000.

${ }^{10}$ См.: Mendegris R., Vermelle G. Le commentaire d'arrêt en droit privé. P., 2004.

${ }^{11}$ См.: Gridel J-P. La dissertation, Le cas pratique et la Consultation en droit privé. P., 2000. 
координация носит предметно-языковой, а также социокультурный характер. Она проявляется в том, что содержание обучения языку специальности (отраженное в программах, учебниках, пособиях) строится с учетом содержания контекста учебного предмета, контекста научного познания, социокультурного контекста содержания профилирующих дисциплин (правовых). Дисциплина «Язык специальности» выступает здесь важным звеном, корректной формой аккумулирования межпредметных знаний, навыков и умений, направленных на становление специальной иноязычной коммуникативной компетентности будущих профессионалов.

На основе базовых положений теории контекстного обучения была разработана модель иноязычной, профессионально ориентированной подготовки нефилологов на примере юристов, специализирующихся в области права международной торговли/международного частного права и регулирования внешнеэкономических связей (двух близких направлений подготовки). Ведущая идея данной модели состоит в том, что специальная иноязычная коммуникативная компетентность выпускников вузов (в нашем случае, юристов указанного профиля подготовки) выступает неотьемлемым, интегративным компонентом в составе целостной социально-профессиональной компетентности молодого специалиста.

\section{Библиографический список}

Богуславский М.М. Международное частное право. М.: Юрист, 2004.

Васильев Е.А. Практикум про гражданскому и торговому праву зарубежных государств. М: Международные отношения, 2005.

Вербицкий А.А. Компетентностный подход и теория контекстного обучения. - М.: Исследовательский центр проблем качества подготовки специалистов, 2004.

Комаров А.С. (под редакцией) Правовое регулирование внешнеэкономической деятельности. М.: Дека, 2001.

Костин А.А. Правовое регулирование внешнеэкономических связей // Учебник по публичному и гражданскому праву в двух томах. Том II. Частное право. М.: Статут, 2008.

Марышева Н.И. Международное частное право. М.: Юрист, 2004.

Gridel J-P. La dissertation, Le cas pratique et la Consultation en droit privé. P., 2000. 
Jacquet J-M, Délebeque Ph., Corneloup S. Droit du commerce international. P., 2007.

Mendegris R., Vermelle G. Le commentaire d'arrêt en droit privé. P., 2004.

Mouralis J-L. Le Cas pratique en droit civil. P., 2000.

\section{French Concept of International Commercial Law}

(Summary)

\section{Natalia P. Homyakova*}

This article presents the French conception of the international commercial law, through the analysis of the manual of the same name widely used in France. Thus, the following number of problems are briefly examined in this article: the subject of the international commercial law, its sources, purposes and "actors" - the 1st chapter; transactions of the international commercial law - the 2nd chapter; dispute settlements (jurisdiction, arbitration) - the 3rd chapter. The conclusion is devoted to the "context-method" teaching recommended by the author to master professional communication.

Keywords: international commercial law; disputes settlement; "contexte-methode" teaching.

\footnotetext{
* Natalia P. Homyakova - Ph.D., assistant professor of the Department of French language No.1, MGIMO-University MFA Russia. homyakova@rambler.ru.
} 